\title{
Case Report: Radical prostatectomy without prostate biopsy in PI-RADS 5 lesions on 3T multi-parametric MRI of the
} prostate gland [version 1; peer review: 1 approved, 1 approved with reservations]

\author{
Andrew Keller ${ }^{1}$, Boon Kua ${ }^{2}$ \\ ${ }^{1}$ Wesley Research Institute, Auchenflower, QLD 4066, Australia \\ 2Wesley Private Hospital, Auchenflower, QLD 4066, Australia
}

\begin{tabular}{l}
\hline F1 First published: 26 Feb 2015, 4:54 \\
https://doi.org/10.12688/f1000research.6171.1 \\
Latest published: 26 Feb 2015, 4:54 \\
https://doi.org/10.12688/f1000research.6171.1 \\
\hline
\end{tabular}

\section{Abstract}

Objective: Current practice mandates a prostate biopsy for histological confirmation of prostate cancer prior to a radical prostatectomy. Prostate biopsy, whether performed trans-rectally or trans-perineally, is an invasive procedure which typically involves an anaesthetic and has the risks of urosepsis, bleeding and haematoma. Post-biopsy inflammatory changes can also obliterate natural tissue planes thereby potentially compromising the quality of a nerve sparing procedure and increasing positive margin rates.

3T-Multi-Parametric Magnetic Resonance Imaging of the Prostate (3T mpMRI-P) is gaining increasing acceptance in the identification and localisation of prostate cancer. In experienced centres, the positive predictive value has been reported to be as high as 95\%.

Methods: Two patients with rising and elevated age- adjusted PSAs and palpable malignant prostate nodules on Digital Rectal Examination (DRE) underwent 3T mpMRI-P. Both patients had Prostate Imaging-Reporting and Data System (PI-RADS) 5 lesions in their peripheral zones corresponding to palpable nodules. Prostate biopsies were offered but declined by both patients. Both were satisfied that there was sufficient evidence on their PSA, DRE and 3T mpMRI-P for a diagnosis of prostate cancer without prostate biopsies and both elected to proceed to a Da Vinci Robotic Assisted Laparoscopic Radical Prostatectomy (RALRP).

Results: Unilateral nerve sparing RALRPs were performed on both patients without complication. Histology demonstrated Gleason 4+4=8 and $4+3=7$ prostate adenocarcinomas, with tumour volumes of $14.92 \mathrm{cc}$ and $4.5 \mathrm{cc}$ respectively.

Conclusions: In appropriately counselled patients who have a high pre-test probability of prostate cancer (rising and elevated PSA, malignant nodule on DRE and a corresponding PI-RADS 5 lesion on 3T

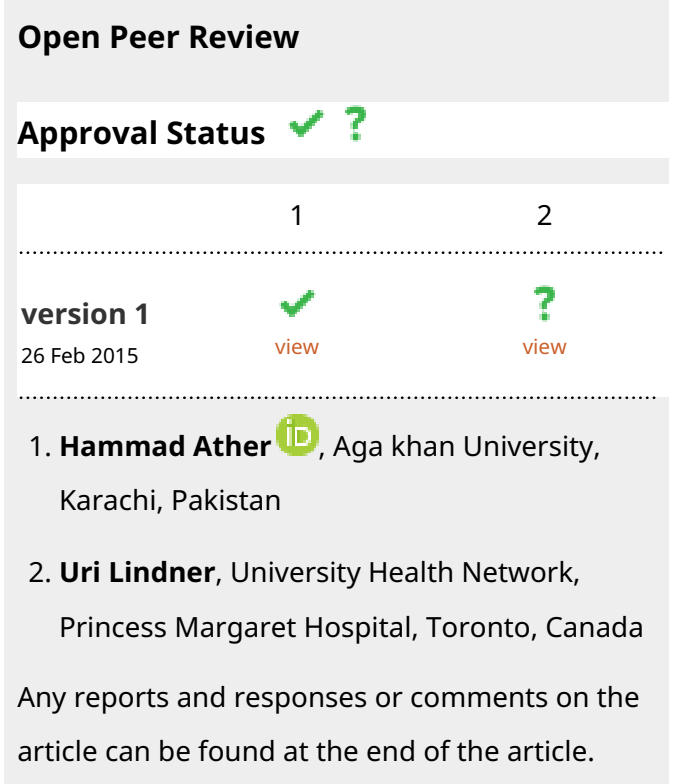


mpMRI-P), it may be appropriate to proceed to a radical prostatectomy without a tissue diagnosis if the patients have strong reservations about prostate biopsy.

\section{Keywords}

Magnetic Resonance Imaging , Prostate cancer , biopsy , diagnostic

test accuracy

Corresponding author: Andrew Keller (andrewthomaskeller@gmail.com)

Competing interests: No competing interests were disclosed.

Grant information: The author(s) declared that no grants were involved in supporting this work.

Copyright: (c) 2015 Keller A and Kua B. This is an open access article distributed under the terms of the Creative Commons Attribution License, which permits unrestricted use, distribution, and reproduction in any medium, provided the original work is properly cited. Data associated with the article are available under the terms of the Creative Commons Zero "No rights reserved" data waiver (CC0 1.0 Public domain dedication).

How to cite this article: Keller A and Kua B. Case Report: Radical prostatectomy without prostate biopsy in PI-RADS 5 lesions on $3 T$ multi-parametric MRI of the prostate gland [version 1; peer review: 1 approved, 1 approved with reservations] F1000Research 2015, 4:54 https://doi.org/10.12688/f1000research.6171.1

First published: 26 Feb 2015, 4:54 https://doi.org/10.12688/f1000research.6171.1 


\section{Introduction}

Current practice mandates a prostate biopsy for histological confirmation of prostate cancer prior to a radical prostatectomy. Prostate biopsy, whether performed trans-rectally or trans-perineally, is an invasive procedure which usually requires an anaesthetic and has the inherent risks of urosepsis, urinary retention and haematoma ${ }^{1,2}$.

Post-biopsy inflammatory changes can also obliterate natural tissue planes there by potentially compromising the quality of a nerve sparing procedure and increase positive margin rates ${ }^{3}$. For this reason prostatectomy is usually delayed by at least 6 weeks to allow for a reduction in the peri-prostatic inflammatory change that follows any biopsy procedure ${ }^{4}$.

The use of 3T mpMRI-p is gaining increasing acceptance for both the diagnosis and localisation of prostate cancer. In experienced centres, the positive predictive value of Prostate Imaging-Reporting and Data System (PI-RADS) 5 lesions has a specificity of $97-100 \%$ in biopsy naïve patients ${ }^{5-8}$. We describe two case reports of radical prostatectomy without tissue diagnosis. The patients involved both had objections to confirmative biopsy, PI-RADS 5 lesions on mpMRI-p and high pre-test probabilities of prostatic malignancy. We believe this report will be of interest for urologists dealing with the dilemma of patients with a high risk of prostatic malignancy, positive mpMRI-p and patient refusal of biopsy procedures.

\section{Case 1}

A 56 year old man was referred to our service with elevated Prostate Specific Antigen (PSA) titres, which had risen progressively from $1.7 \mathrm{ng} / \mathrm{mL}$ to $4.6 \mathrm{ng} / \mathrm{mL}$ over a five year period. He had a positive family history of prostate cancer (PC), with his brother having undergone radical prostatectomy 5 years earlier. His digital rectal exam (DRE) showed a malignant nodule in his right lobe and a firm contralateral lobe.

We requested a 3-Tesla Multi-parametric Magnetic Resonance Imaging of the prostate (mpMRI-p) which identified a Prostate Imaging-Reporting and Data System (PI-RADS) 5 lesion in the right lobe of the prostate with probable extra-prostatic extension (Figure 1). A smaller lesion was present in the left mid peripheral zone (Figure 2) with possible left external iliac node involvement. Staging Computerised Tomography (CT) of the abdomen and pelvis and Tc-99m bone scan showed no radiological evidence of metastatic spread other than the previously mentioned borderline enlarged left external iliac nodes.

The results of the investigations (PSA titres, DRE) and the chance of a false positive mpMRI-p result of approximately $5 \%$ was explained to the patient. The patient was adamantly against undergoing confirmatory prostate biopsy as he was concerned about biopsy related sepsis. He also reported pre-existing anxiety regarding PC since his brother had been diagnosed and treated.

The patient subsequently underwent a bilateral incremental nerve sparing Robot Assisted Laparoscopic Radical Prostatectomy (RALRP) with left sided extended pelvic lymph node dissection.

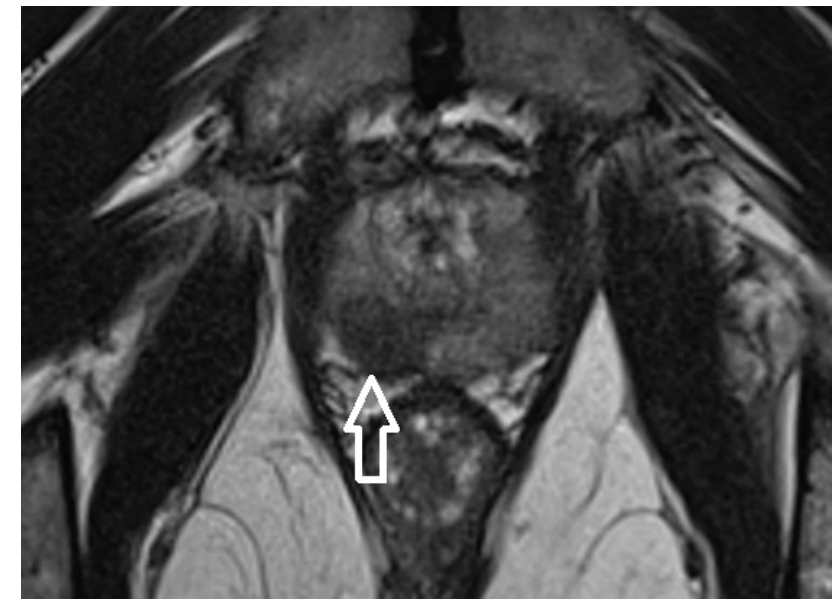

Figure 1. Patient 1: Axial T2 weighted MR showing large posterior hypo-intense lesion with EPE.

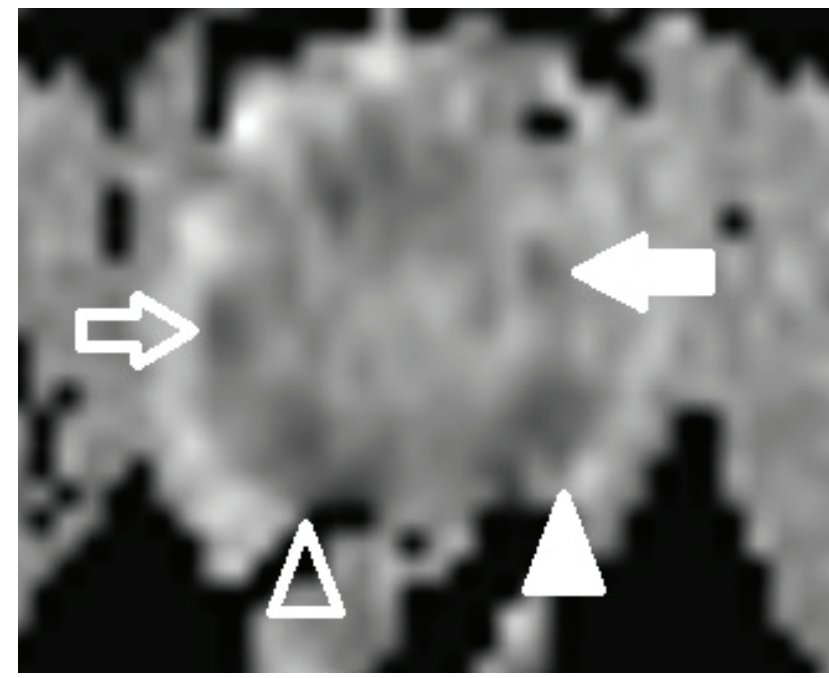

Figure 2. Patient 1: Apparent Diffusion Co-efficient (ADC) map, showing bilateral posterior lesions (arrowheads) and bilateral mid zone lesions (arrows).

The Operative specimen's histology demonstrated Gleason $4+3=7$ primary tumour with tertiary pattern 5 present (Figure 3 ) with extraprostatic extension (EPE) present. Peri-neural invasion was present (Figure 4). A focally positive margin at region of EPE was present over a $0.5 \mathrm{~mm}$ base. The specimen's histological stage was T3a (AJCC $7^{\text {th }}$ Edition 2010).

The patient made an uneventful recovery from surgery. Postoperative incontinence was mild at 6 weeks, using a single safety pad during the day only. He is trialling sildenafil for his post-operative erectile dysfunction. His PSA at 5 weeks was low at $0.033 \mathrm{ng} / \mathrm{mL}$. His follow-up is ongoing. 


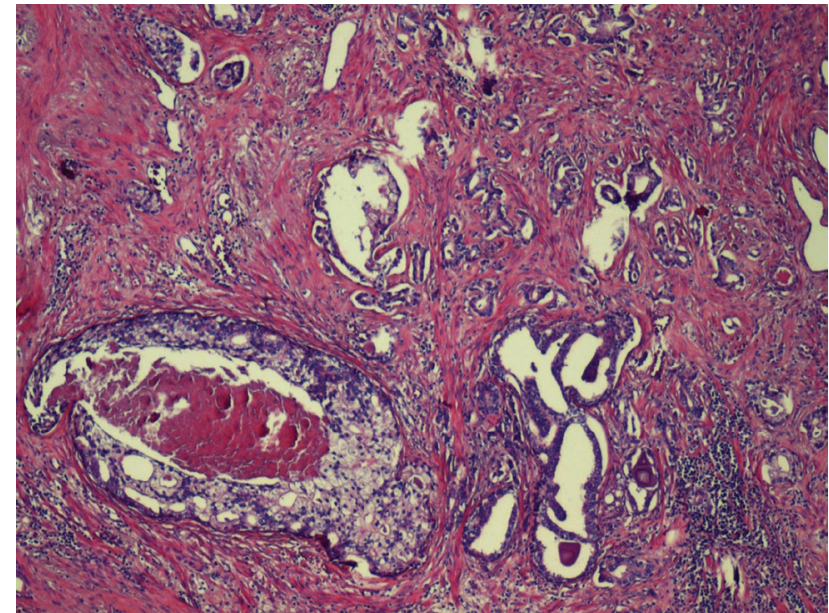

Figure 3. Patient 1: H+E stain, low power view. The operative specimen demonstrated Gleason score $4+3=7$ prostatic adenocarcinoma with a tertiary component of Gleason pattern 5. Cribiform glands with comedonecrosis represent Gleason pattern 5.

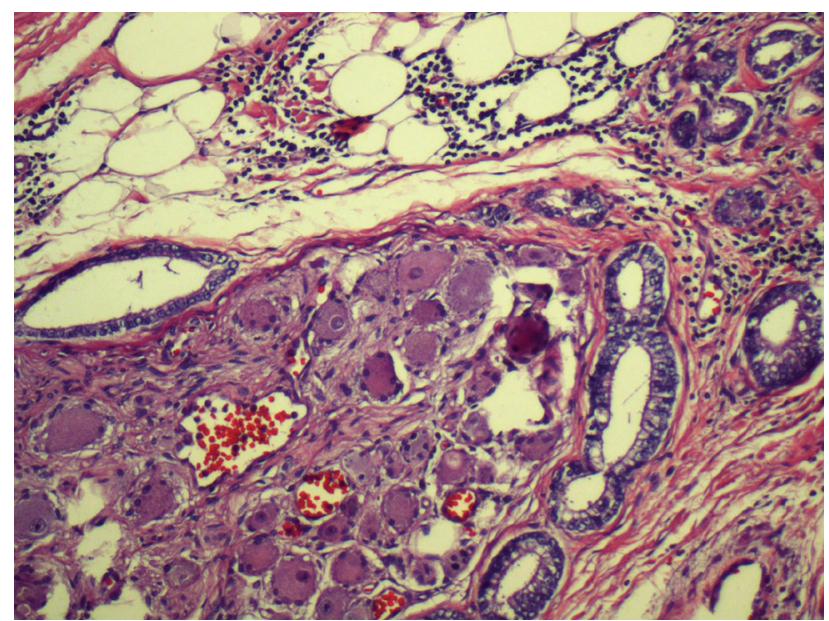

Figure 4. Patient 1: H+E stain, high magnification view of right nerve bundle with invasion by prostate cancer.

\section{Case 2}

A 64 year old with no family history of prostate cancer and an elevated serum PSA of $9 \mathrm{ng} / \mathrm{mL}$ was refereed to our service. His DRE revealed a right sided palpable prostate nodule with extension into the ipsilateral seminal vesicle.

mpMRI-p was requested and confirmed a PI-RADS 5 lesion in the right base and mid-zone of the gland (Figure 5). The lesion extended across midline into the left lobe. Diffusion restriction was present on ADC map (Figure 6). Right-sided seminal vesicle invasion was also demonstrated radiologically (Figure 7).

The patient was advised to undergo confirmatory prostate biopsy but declined, being satisfied with his diagnosis based on PSA, DRE and Mp-MRI-p findings. CT and Tc-99m bone scans were negative for metastatic spread.

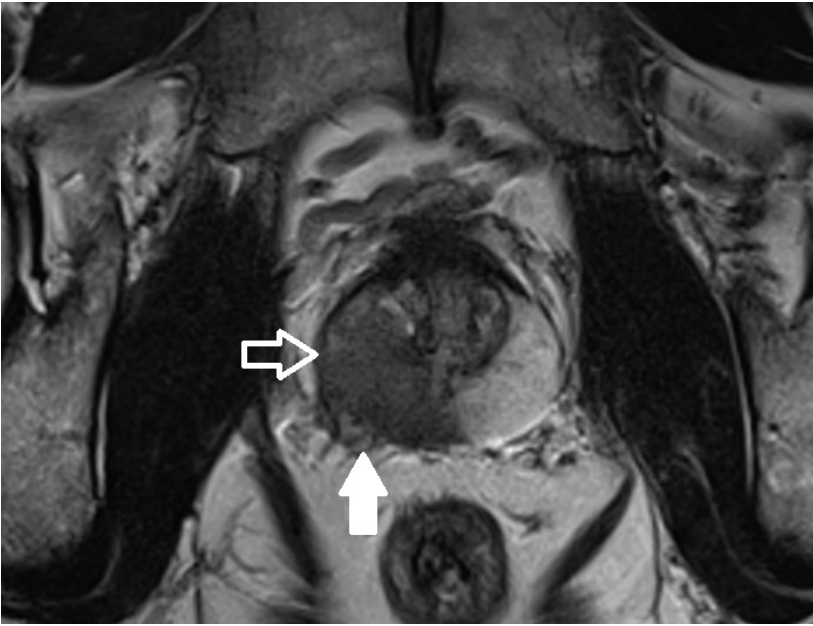

Figure 5. Patient 2: T2-weighted MR of prostate, showing marked T2 signal involving the whole of the $R$ lobe in this image (hollow arrow), extending across the midline and demonstrating focal extra-prostatic extension (solid arrow).

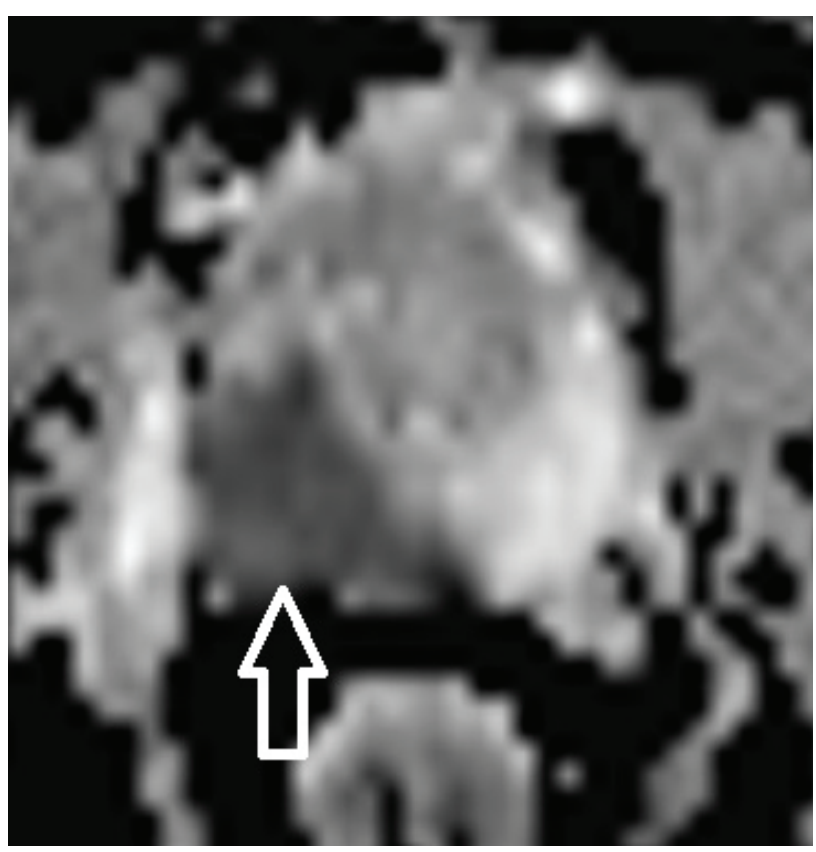

Figure 6. Patient 2: ADC map showing large right sided area of diffusion restriction in region of the T2 hypo-intensity.

The patient underwent RALRP. Due to his seminal vesicle invasion a wide non-nerve sparing approach was taken on the right side, with the contralateral nerve bundle spared due to the patient being sexually active. A right sided obturator node dissection was performed concurrently.

Histology demonstrated Gleason $4+4$ with tertiary pattern 5 (Figure 8). Tumour volume was $14.92 \mathrm{cc}$. Right neurovascular bundle invasion and bilateral seminal vesicle invasion was present (Figure 9). All resection margins were uninvolved and 0/3 resected 


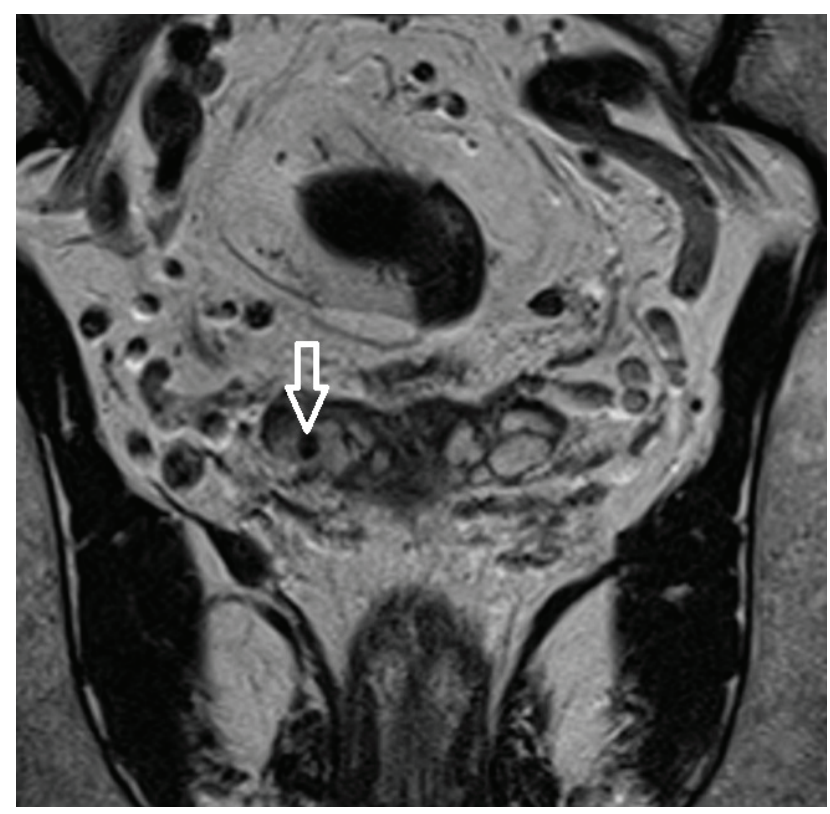

Figure 7. Patient 2: T2 weighted coronal MR of prostate demonstrating solid lesion in the right seminal vesicle (arrow).

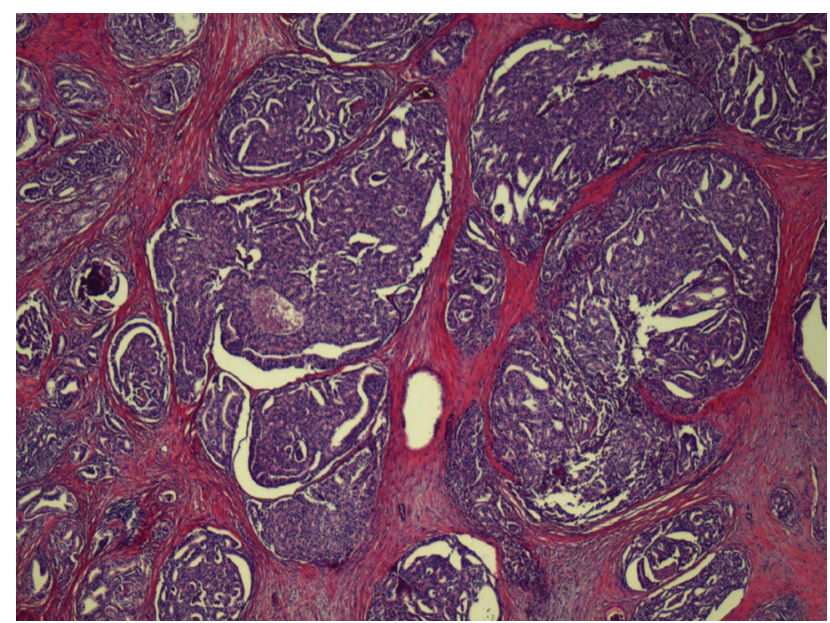

Figure 8. Patient 2: H+E stain, low power view, showing regions of Gleason score $4+5=9$ prostate adenocarcinoma.

nodes were infiltrated by malignancy. His tumours histologic stage was T3b (AJCC $7^{\text {th }}$ Edition 2010).

The patient made a good recovery following his surgery. Postoperatively his early urinary incontinence was very mild, using a single safety pad per day. His erectile dysfunction is successfully managed with sildenafil.

Initially, at 2 months post-operatively his PSA was undetectable, however, at 5 months it had risen to $0.03 \mathrm{ng} / \mathrm{mL}$, and by 9 months

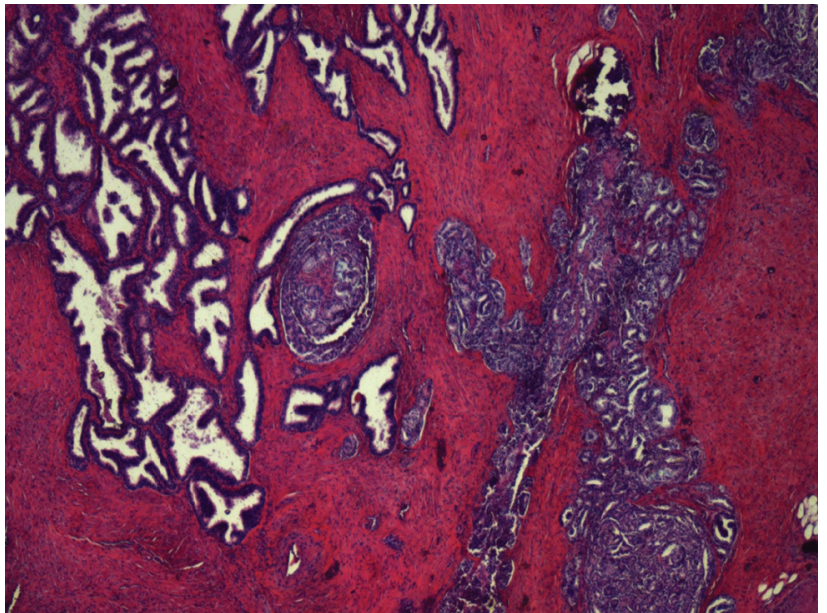

Figure 9. Patient 2: H+E stain, low power view demonstrating seminal vesicle invasion that was identified on the pre-operative mp-MRI-p.

post-operatively it had risen further to $0.14 \mathrm{ng} / \mathrm{mL}$. He was subsequently referred to radiation oncology for salvage radiotherapy for biochemical failure.

\section{Discussion}

Both patients in our small case series were diagnosed and their tumours correctly localised by mpMRI-p. Whilst we strongly recommended both patients proceeded to confirmative prostate biopsies, they both declined further investigation. Both patients had high pre-test probabilities of malignancy even prior to their positive mpMRI-p findings and were satisfied that their diagnoses were correct, and had concerns about the risks of prostate biopsy. They were both informed of and willing to accept the small risk of a false positive diagnosis.

It is important to note that radical prostatectomy without tissue diagnosis is not recommended as standard practice by the authors, even with a PI-RADS 5 lesion on mp-MRI-p. The case studies presented here are exceptional cases where both patients had strong opposition to biopsy despite counselling otherwise. Whilst mpMRI-p has demonstrated great sensitivity and specificity for identification of high risk prostate cancer, there remains the possibility of over diagnosis, and consequent overtreatment if a confirmatory biopsy is not also obtained pre-operatively. With further development of this imaging technology it is plausible that in the future, high risk patients with PI-RADS 5 lesions on mpMRI-p could undergo a radical prostatectomy without the need for a prostate biopsy. While we have successfully performed two prostatectomies without pre-operative biopsy we do not advocate this as a standard approach.

\section{Conclusion}

In exceptional circumstances and with appropriately counselled patients who have a high pre-test probability of prostate cancer (rising and elevated PSA, malignant nodule on DRE and a corresponding 
PIRADS 5 lesion on mpMRI-P), it may be appropriate to proceed to a radical prostatectomy without a prostate biopsy. Further advancements in mpMRI-p imaging techniques may negate the need for routine biopsies in high risk lesions prior to prostatectomy, but this cannot be recommended as routine practice with currently available imaging protocols.

\section{Consent}

Written informed consent for publication of their clinical details and clinical images was obtained from the patients.
Author contributions

AK writing and literature review. BK concept of article and proofing of article. Both authors agreed to the final content of the manuscript.

Competing interests

No competing interests were disclosed.

\section{Grant information}

The author(s) declared that no grants were involved in supporting this work.
1. Norberg M, Holmberg L, Haggman M, et al.: Determinants of complications after multiple transrectal core biopsies of the prostate. Eur Radiol. 1996; 6(4): 457-61.

PubMed Abstract | Publisher Full Text

2. Lange $D$, Zappavigna $C$, Hamidizadeh $R$, et al.: Bacterial sepsis after prostate biopsy--a new perspective. Urology. 2009; 74(6): 1200-5. PubMed Abstract | Publisher Full Text

3. Shah JB, McKiernan JM, Elkin EP, et al:: Prostate biopsy patterns in the CaPSURE database: evolution with time and impact on outcome after prostatectomy. J Urol. 2008; 179(1): 136-40. PubMed Abstract | Publisher Full Text

4. Martin GL, Nunez RN, Humphreys MD, et al: Interval from prostate biopsy to robot-assisted radical prostatectomy: effects on perioperative outcomes. BJU Int. 2009; 104(11): 1734-7. PubMed Abstract | Publisher Full Text

5. Thompson JE, Moses D, Shnier $\mathrm{R}$, et al: Multiparametric magnetic resonance imaging guided diagnostic biopsy detects significant prostate cancer and could reduce unnecessary biopsies and over detection: a prospective study.
J Urol. 2014; 192(1): 67-74.

PubMed Abstract | Publisher Full Text

6. Ni Mhurchu E, O'Kelly F, Collins CD, et al:: Pi-RADS in Practice - The Predictive Value of Pi-RADS Scoring in Targeted Prostate Biopsies for Patients with Elevated PSA, and Previous Negative Biopsies. Radiological Society of North America 2013 Scientific Assembly and Annual Meeting, December 1 - December 6, 2013, Chicago IL Accessed July 22, 2014. 2013.

Reference Source

7. Grey $A D$, Chana M, Popert $R$, et al.: Diagnostic accuracy of magnetic resonance imaging (MRI) prostate imaging reporting and data system (PI-RADS) scoring in a transperineal prostate biopsy setting. BJU Int. 2014.

PubMed Abstract | Publisher Full Text

8. Pokorny MR, de Rooij M, Duncan E, et al.: Prospective study of diagnostic accuracy comparing prostate cancer detection by transrectal ultrasoundguided biopsy versus magnetic resonance (MR) imaging with subsequent MR-guided biopsy in men without previous prostate biopsies. Eur Urol. 2014; 66(1): 22-9.

PubMed Abstract | Publisher Full Text 


\title{
Open Peer Review
}

\section{Current Peer Review Status:}

\section{Version 1}

Reviewer Report 13 July 2015

https://doi.org/10.5256/f1000research.6615.r9397

(C) $\mathbf{2 0 1 5}$ Lindner $\mathbf{U}$. This is an open access peer review report distributed under the terms of the Creative Commons Attribution License, which permits unrestricted use, distribution, and reproduction in any medium, provided the original work is properly cited.

\begin{abstract}
Uri Lindner
Department of Surgical Oncology, Division of Urology, University Health Network, Princess Margaret Hospital, Toronto, ON, Canada

In this case report the authors describe two cases of patients highly suspicious for prostate cancer based on PSA levels, physical examination and MRI who underwent surgery and the final pathology coincided with the presumed diagnosis.

It is not clear what is the benefit of undergoing major surgery without confirmed diagnosis, on the contrary, today we are moving forward and advocating for tissue diagnosis prior to oncological surgery.

If the MRI is highly suspicious for tumor one can advocate for MRI/US fusion biopsy and reducing the number of cores taken to a minimum.

Competing Interests: No competing interests were disclosed.

I confirm that I have read this submission and believe that I have an appropriate level of expertise to confirm that it is of an acceptable scientific standard, however I have significant reservations, as outlined above.
\end{abstract}

Author Response 13 Jul 2015

Andrew Keller, Wesley Research Institute, Auchenflower, Australia

Thanks for your comments Dr. Lindner.

Whilst there are a few potential benefits for undertaking major surgery without first obtaining histo-pathological diagnosis (zero risk of biopsy related sepsis, no obliteration of tissue planes by post-biopsy inflammation) the authors do not argue that those benefits outweigh the risk of a false diagnosis. Indeed, the benefits of tissue confirmation of 
malignancy prior to a potentially morbid procedure such as prostatectomy cannot be understated. Instead, this article describes two cases where both patients had significant anxiety regarding their potential diagnosis of prostate cancer. Both patients were counselled on the potential false positive rate of mp-MRI-p and were counselled to have their clinical diagnosis confirmed via biopsy but both declined. Such was their anxiety despite reassurances from the surgeon, that both patients insisted on prostatectomy despite being warned of the risk of potentially benign operative histology. It is possible that even negative pre-operative biopsy might not have allayed their concern.

It must be emphasized that the authors do not advocate prostatectomy without biopsy as standard practice. The current specificity of mp-MRI-p is insufficient for confident diagnosis without confirmatory biopsy. In these cases, however, where due to patient factors biopsy was not possible, mp-MRI-p was invaluable in correctly identifying tumour location in order to facilitate prostatectomy.

Competing Interests: No competing interests were disclosed.

Reviewer Report 13 March 2015

https://doi.org/10.5256/f1000research.6615.r7952

(C) 2015 Ather H. This is an open access peer review report distributed under the terms of the Creative Commons Attribution License, which permits unrestricted use, distribution, and reproduction in any medium, provided the original work is properly cited.

\section{Hammad Ather}

Section of Urology, Aga khan University, Karachi, Pakistan

It is an interesting series of two cases. Indeed the basic premise of the authors' for proceeding with treatment of prostate cancer due to complications related with TRUS guided biopsy. Treating prostate by radical surgery without prior biopsy confirmation is challenging the age old dictum in oncology that cancer should not be treated until histologically proven.

MRI imaging of the pelvis has improved significantly with the introduction of DW and MP technology. However, confirmation and final diagnosis of cancer remains a histologist domain. I have following observations on the current submission for the authors' to comment

1. The reference cited 1,2 are relatively old, better pain control and improved in the TRUS technology and understanding the potential causes of infective complications are better understood now. the insidence of complication related to biopsy has decreased considerably.

2. Although patients have given an informed consent there is a small possibility of not detecting cancer in the final pathology. Are there any medico legal implications.

Competing Interests: No competing interests were disclosed. 


\section{I confirm that I have read this submission and believe that I have an appropriate level of expertise to confirm that it is of an acceptable scientific standard.}

\section{Author Response 23 Mar 2015}

Andrew Keller, Wesley Research Institute, Auchenflower, Australia

Dr. Ather, thanks for your comments.

I agree with you that while the new imaging technologies are exciting that diagnosis should remain, for the most part histological. These two cases were the exceptions to the rule, and due to patient, rather than surgeon preference.

In regards to your comments, whilst pain can certainly be controlled in the TRUS setting with use of twilight sedation, our experience is that even with more intensive regimens of antibiotics the rates of TRUS sepsis are increasing, mostly due to increased prevalence of ciprofloxacin-resistant E. Coli.

Secondly, both patients did give informed consent for the prostatectomy, including very clearly being told that there was a chance of a false positive diagnosis from the MR scanning. There are numerous examples of legal action in spite of informed consent of risks and I can see certain patients suing in the event of benign pathology.

Competing Interests: No competing interests were disclosed.

The benefits of publishing with F1000Research:

- Your article is published within days, with no editorial bias

- You can publish traditional articles, null/negative results, case reports, data notes and more

- The peer review process is transparent and collaborative

- Your article is indexed in PubMed after passing peer review

- Dedicated customer support at every stage

For pre-submission enquiries, contact research@f1000.com 